\title{
EARTHQUAKE RESISTANT DESIGN OF UNDERGROUND STRUCTURES AND PIPES
}

\author{
DIETER KRAUS \\ University of the German Armed Forces Munich \\ Werner Heisenberg Weg 99 \\ 8014 Neubiberg / Germany
}

SUMMARY. Underground Structures and Pipes can be analysed as slender structures completely embedded in the soil.

For the dynamical analysis soil and structure can be investigated by decoupled structural models. The horizontal layer system of the soil is modeled as a shear beam while for the structure a flexural beam is used

Both models will be finally coupled by elastic foundation.

\section{INTRODUCTION}

For an earthquake resistant design usually the following verifications have to be carried out:

(1) Stress and strain in longitudinal direction of the structure, due to the earthquake waves which are travelling through the soil.

The structure has to follow the displacements of the soil, this yields to bending moments, shear forces and axial forces in longitudinal direction. In case of joints, the movements of the joints has to be determined to design the joint - construction.

(2) Stress and strain in transverse direction of the structure, due to the reduced internal friction of the soil.

Depending on the vibrations the internal friction of the soil can significant decrease up to zero. This effect is called [1] "soil liquifaction".

Since soil and structure move largely together, for the calculation in transverse direction the assumptions of the "earth pressure at rest" considering the actual internal friction can be used.

\section{NOTATIONS}

$x, y, z:$ coordinates
$u, v: \quad$ displacements
$\varepsilon, \gamma: \quad$ strains
$\rho: \quad$ mass density
$E: \quad$ modulus of elasticity of the soil
$G: \quad$ modulus of shear of the soil
$\mu: \quad$ Poisson's ratio of the soil
$c_{s}: \quad$ shear wave velocity
$c_{p}: \quad$ compressional wave velocity
$\lambda: \quad$ wave length
$f_{n}: \quad$ n-th frequency

$\begin{array}{ll}\omega_{n}: & n \text {-th circular frequency } \\ \phi_{n}: & n \text {-th mode } \\ \Gamma_{n}: & \text { participation factor of the } n \text {-th mode } \\ D: & \text { damping ratio } \\ D_{n}: & \text { modal damping of the } n \text {-th mode } \\ (E J)_{B}: & \text { bending stiffnes of the structure } \\ D_{n}: & \text { average modal damping of the } n \text {-th mode } \\ S_{a}: & \text { the acceleration of the soil elements otick } \\ L: & \text { with the structure } \\ \ell: & \text { characteristic length of the Winkler beam } \\ & \text { length of the structure }\end{array}$




\section{GENERAL ASSUMPTIONS}

Mass distribution and stiffness of the structure does not effect the vibration behaviour of the soil - it is therefore sufficient to investigate as a first step only the dynamical response of the soil.

The deflections of the soil due to an earthquake can be analysed by using the wave propagation theory. The corresponding vibration model of the soil is assumed as a infinite horizontal layer system. Only shear wave effect has to be taken under consideration.

Stress and strain of the structure are then analysed by the assumption that the structure follows the movements of the soil with only small relative deflections between soil and structure.

\section{DYNAMICAL ANALYSIS OF THE SOIL}

Dynamical phenomenons in the soil can be described by the theory of wave propagation in a half space.

Two groups of waves have to be distinguished

- Body waves

- Surface waves

In the group of the body waves (see Fig. 1) we know shear waves respectively $S$-Wave and compressional waves respectively $P$-Wave and in the group of the surface waves we distinguish RayleighWave and Love-Waves.

The influence of the surface waves is limited of a relatively small area. For the following design suggestion surface waves are therefore neglected.

In case of shear-waves, soil particles move perpendicular to the wave propagation. The corresponding stress strain state is of pure shear; the material does not changes its volume.

a)

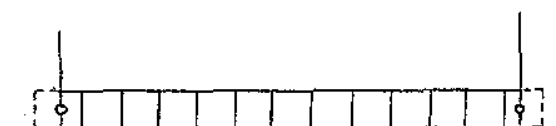

b)

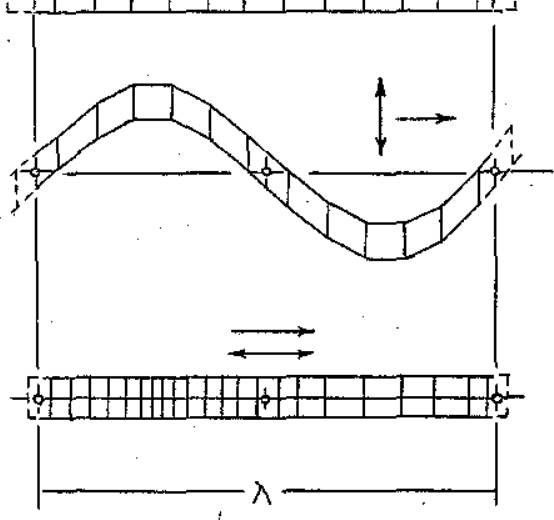

$\rightarrow$ direction of wave propagation

$\longleftrightarrow$ direction of soil movements

a) bar at rest,

In case of compressional waves, soil movements and wave propagation have the same direction. The corresponding state of stress and strain is axial. The elements of the soil are stretched and compressed.

Due to the different wave velocities compressional waves are much faster than shear waves. This means that $S$-Waves and $P$-Waves do not affect the structure at the same time.

On the other hand the movements, corresponding to the shear waves are much bigger as in case of compressional waves.

For practical investigations it is therefore sufficient to consider only shear wave effect.

The differential equations of the wave propagation [4] in a solid body can be found by the equilibrium of the d'Alembert forces (Fig. 2) and the alteration of the elastic state of stress.

Fig. 1. Demonetration of the body waves at a single bar b) shear wave $/ S$-wave, c) compressional wave/ $P$-wave

a)

$$
\rho \frac{\partial^{2} v}{\partial t^{2}} d x d y d z
$$

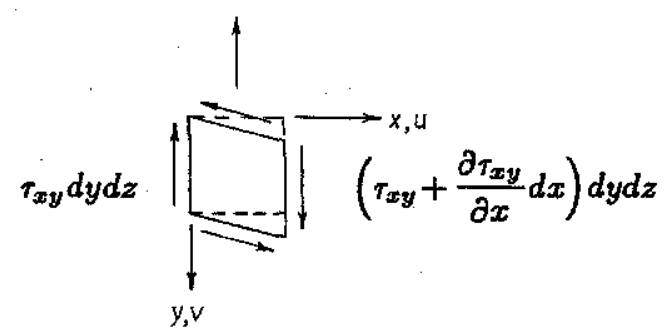

b)

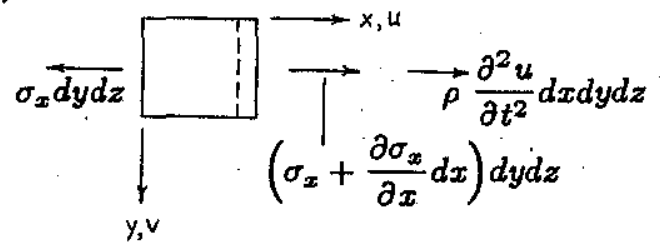

Fig. Q. Equilibrium condition at a soil element

a) pure shear wave action, b) pure compressional wave action 


$$
\begin{aligned}
& \frac{\partial^{2} v}{\partial t^{2}}=c_{s}^{2} \frac{\partial^{2} v}{\partial x^{2}} \\
& \frac{\partial^{2} u}{\partial t^{2}}=c_{p}^{2} \frac{\partial^{2} u}{\partial x^{2}}
\end{aligned}
$$

In equations (4.1) and (4.2) $c_{s}$ and $c_{p}$ means the shear wave velocity and the compressional wave velocity

$$
\begin{aligned}
& c_{s}=\sqrt{\frac{G}{\rho}} \\
& c_{p}=\sqrt{\frac{E}{\rho} \frac{(1-\mu)}{(1+\mu) \cdot(1-2 \mu)}}
\end{aligned}
$$

Equation (4.5a) is a solution of (4.1). In this expression the wave length $\lambda_{n}$ can be substituted by $\lambda_{n}=c_{s} / f_{n}$.

$$
\begin{aligned}
& v=v_{0, n} \sin \frac{2 \pi}{\lambda_{n}}\left(x-c_{s} t\right) \\
& v=v_{0, n} \sin \frac{2 \pi f_{n}}{c_{s}}\left(x-c_{s} t\right)
\end{aligned}
$$

To describe the complete shape of the shear wave we have to determine a displacement $v_{0, n}$ and a frequency $f_{n}$.

To calculate the displacement and the frequency caused by shear deformations, the soil can be modeled as an infinite layer system [2, 3](Fig. 3). This layer system can further simplified as a shear beam. If we want to use conventional computer programms the shear beam can be substituted by an flexural beam with the bending stiffness $B_{i}$, lumped masses $N_{i}$ and the condition that the angel of rotation at each node is zero.

$$
\begin{aligned}
B_{i} & =G_{i} \frac{h_{i}^{2}}{12} A \\
M_{i} & =\frac{A}{2}\left(\rho_{i-1} h_{i-1}+\rho_{i} h_{i}\right)
\end{aligned}
$$

For the dynamical analysis (Fig.4) the response spectrum method may be used, provided that a spectrum for the bedrock of the layer system is available.

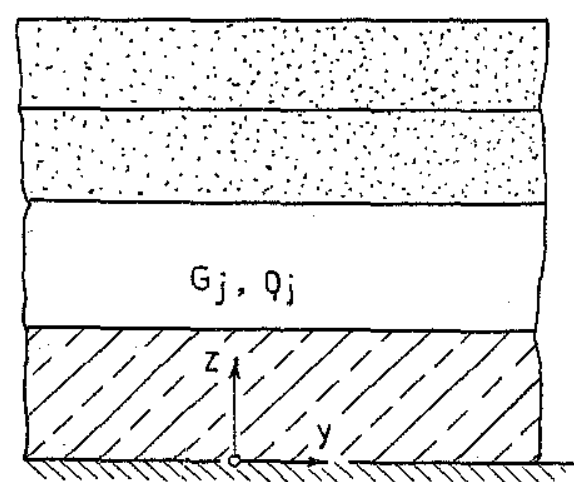

c)

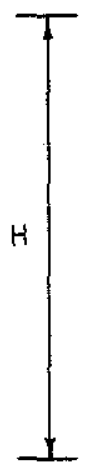

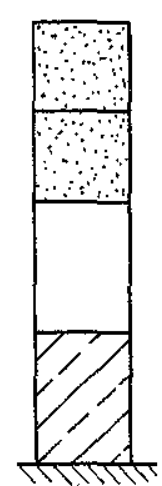

b)

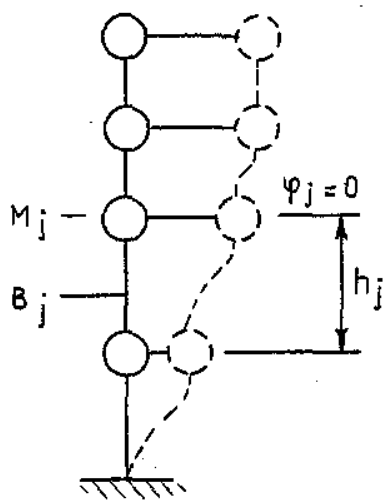

c)

Fig. 9. Vibration model of the soil

a) infinite parallel layer system, b) equivalent shear beam, c) equivalent beam with bending flexure 

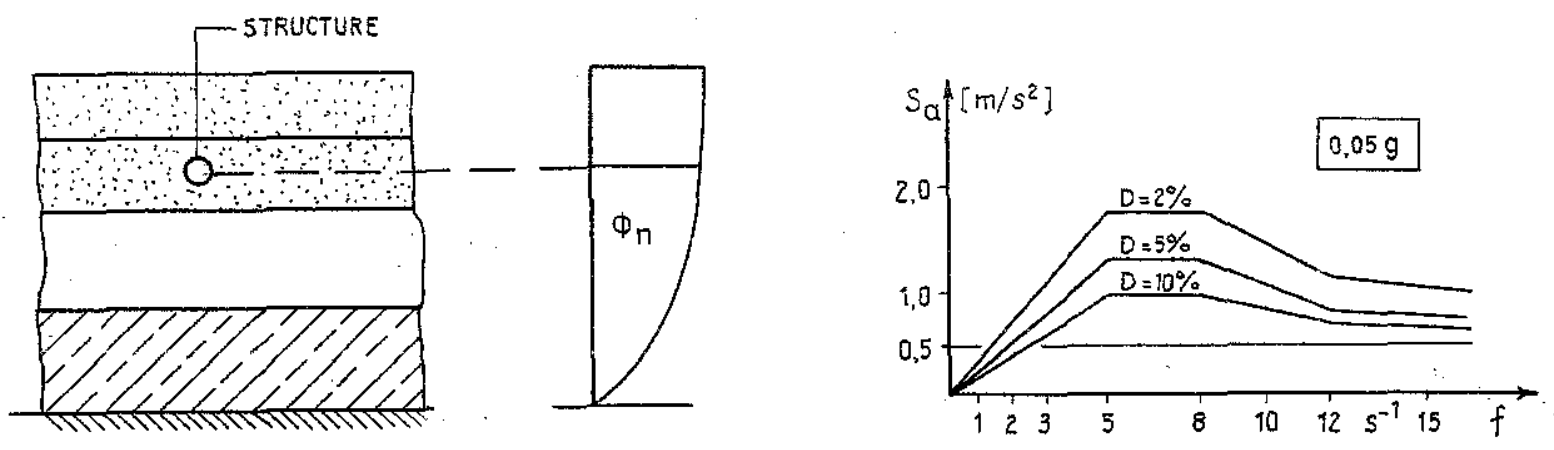

$n$-th Mode

Fig. 4. Dynamical analysis of the soil

The acceleration of a certain mode is found by the following, well known expressions.

$$
\begin{aligned}
a_{n} & =\phi_{n} \Gamma_{n} S_{a}\left(f_{n}, \bar{D}_{n}\right) \\
v_{0, n} & =\frac{a_{n}}{\left(2 \pi f_{n}\right)^{2}}
\end{aligned}
$$

\section{STRESS RESULTANTS}

Stress and strain of the structure are then analysed under the assumption that the structure follows the displacements of the soil.

This means, that the deflection curve of the structure is equal to the shape of the wave.

Soil structure interaction has no significant influence on the vibration behaviour of the slender structure.

In case that the wave propagates in the same direction (Fig.5) as the structure $(\alpha=0)$, the stress resultants are found from the product of the bending stiffness of the structure and the corresponding derivations of the shear wave displacements.

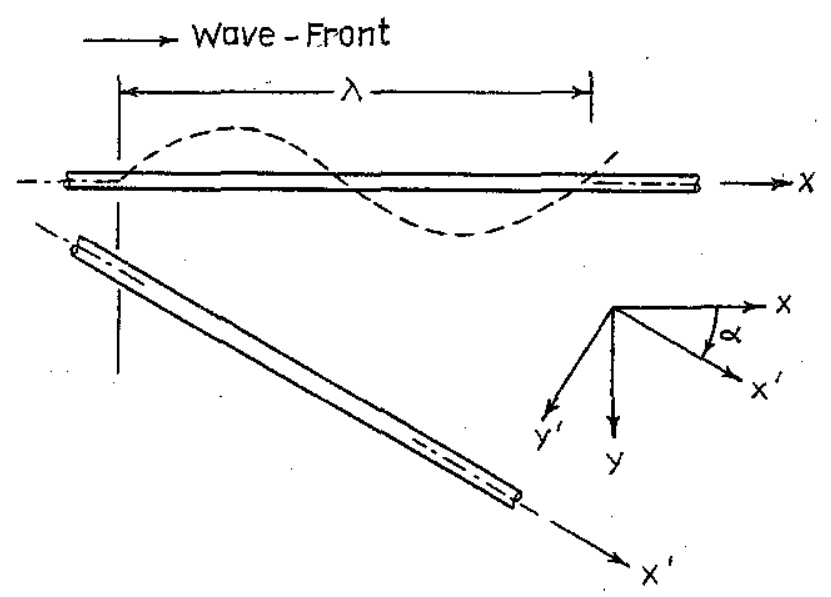

Fig. 5. Propagation direction of the wave front

$$
\begin{aligned}
& M_{n}= \pm(E J)_{B} v_{0, n}\left(\frac{2 \pi}{c_{s}} f_{n}\right)^{2} \\
& Q_{n}= \pm(E J)_{B} v_{0, n}\left(\frac{2 \pi}{c_{s}} f_{n}\right)^{3} \\
& P_{n}= \pm(E J)_{B} v_{0, n}\left(\frac{2 \pi}{c_{s}} f_{n}\right)^{4} \\
& N_{n}=0
\end{aligned}
$$


The so far described method works under the assumption, that the elastic foundation between soil and structure is stiff enough, that there occur no relative displacements between soil and structure. Soil - structrure - interaction is of minor influence.

The relation between the displacement of the soil and the displacement of the structure (Fig. 6) can be estimated by the following equation

with

$$
\frac{v_{B}}{v_{0, n}}=\frac{0.0026\left(\frac{\lambda_{n}}{L}\right)^{4}}{1+0.0026\left(\frac{\lambda_{n}}{L}\right)^{4}}
$$

$$
L=\sqrt{\frac{(E J)_{B}}{G}}
$$

The corresponding parameters are the wave length $\lambda$ and the characteristic length $L$, which is describing the elastic foundation between the structure and the soil.
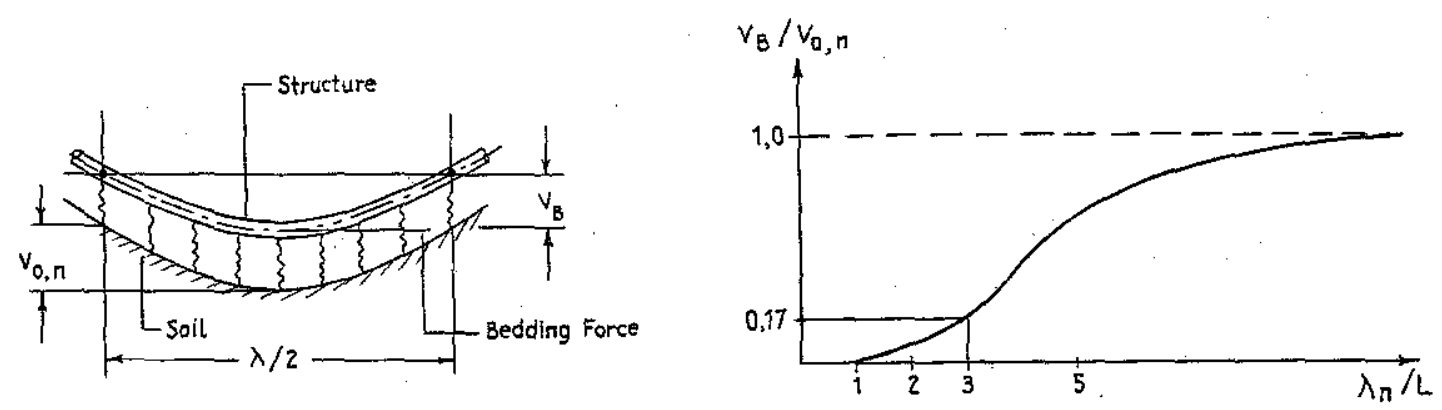

Fig. 6. Soil structure interaction

This equation is derived by imposing the soil a statical sinus shaped deflection and the distribution of the bedding forces are also sinus shaped.

With this equation the influence of higher modes can be estimated very easyly.

Higher frequencies yield to a shorter wave length. For ratios $\lambda / L$ less than 3 the displacement of the structure is less than $20 \%$. In this case the soil displacement will not be transmitted on the structure. The structure remains in rest.

The stress resultants can be significant reduced and influenced by the arrangement of joints.

In a joint the bending moment vanishes while shear forces usually can be transmitted by the joint construction.

The influence of joints can investigated by using a beam on elastic foundation.

If for instance the distance of the joints is a quater of the wave length (see Fig. 7a) we will find the reduced stress resultants by superponing the systems (4.1) and (4.2).

With the diagrammas of Fig. 7 (b) and (c) the reduction factors for bending moments $\eta_{M}$ and for the shear force at the joint $\eta_{Q}$ can be found. The corresponding parameters are the wave length the characteristic length $L$ and the distance $\ell$ between the joints.

The calculation may be carried out by the following steps:

(1) Calculation of the stress resultants of an infinite structure and for the individual modes acc. to chapter 4 and 5

$$
\begin{aligned}
M_{n} & = \pm(E J)_{B} \frac{a_{n}}{c_{s}^{2}} \\
Q_{0, n} & = \pm(E J)_{B} \frac{2 \pi f_{n}}{c_{s}^{3}} a_{n}
\end{aligned}
$$

Modes with a ration $\lambda / L$ less than 3.0 may be neclected 


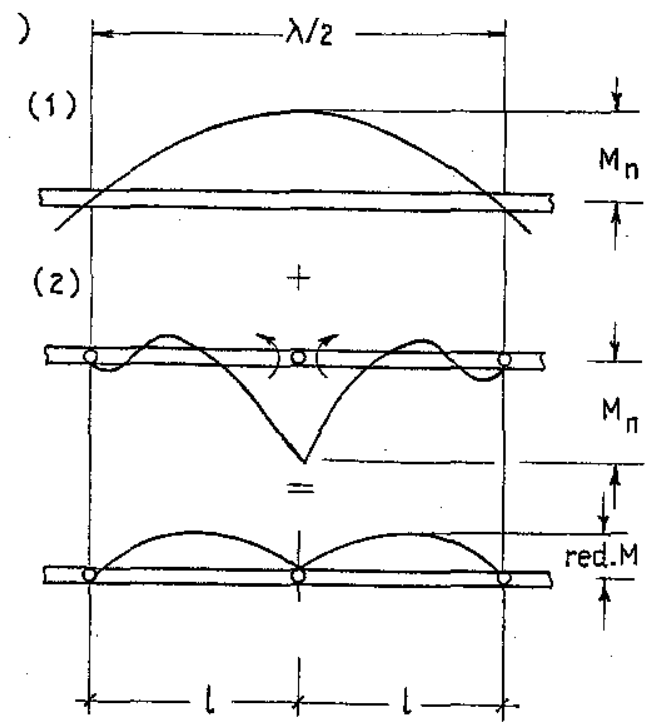

b) $\quad \eta_{M}=\operatorname{red} \cdot M_{n} / M_{n}$

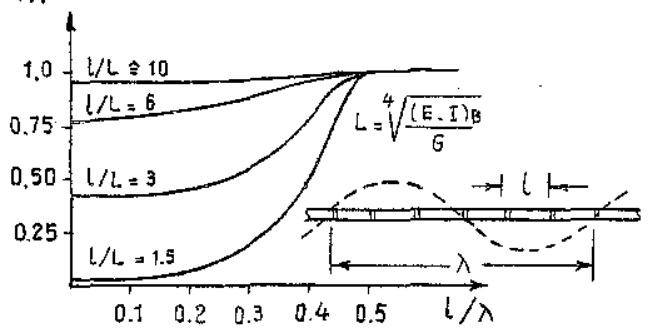

c) $\quad \eta_{Q}=\operatorname{red} Q_{0, n} / Q_{0, n}$

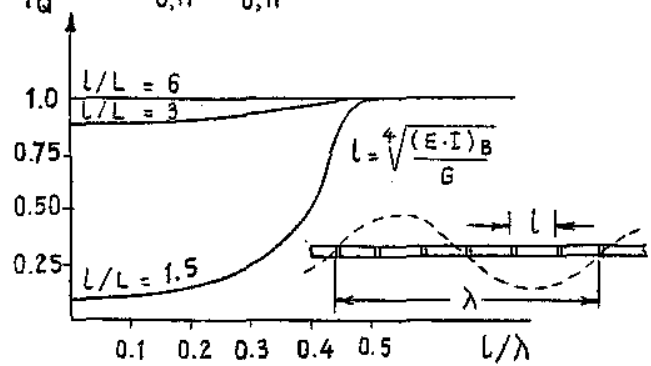

Fig. 7. Reduction of stress resultants due to joints

a) superposition method for bending moments, b) reduction for bending moments, c) reduction for shear forces at the joints

(2) In case of joints the reduction factors $\eta_{M}$ and $\eta_{Q}$ may picked up from the diagramms of Fig.7.

$$
\begin{aligned}
\operatorname{red} M_{n} & =M_{n} \eta_{M} \\
\operatorname{red} Q_{0, n} & =Q_{0, n} \eta_{Q}
\end{aligned}
$$

(3) Superposition of the individual modes. The simplest and most popular suggestion for this superposition is the square root of the sum of the squares.

$$
\begin{aligned}
\max , \operatorname{red} M & =\sqrt{\sum\left(\operatorname{red} M_{n}\right)^{2}} \\
\max , \operatorname{red} Q_{0} & =\sqrt{\sum_{n}\left(\operatorname{red} Q_{0, n}\right)^{2}}
\end{aligned}
$$

The movements of the joints can be rough estimated by the following equations (see Fig. 8)

$$
\begin{aligned}
\Delta K & =\frac{a}{c_{s}^{2}} \cdot \frac{\ell b}{2} \\
\Delta \varepsilon & =\frac{\dot{v}}{2 c_{s}} \ell
\end{aligned}
$$

The joint construction must be able to resist this movements. 


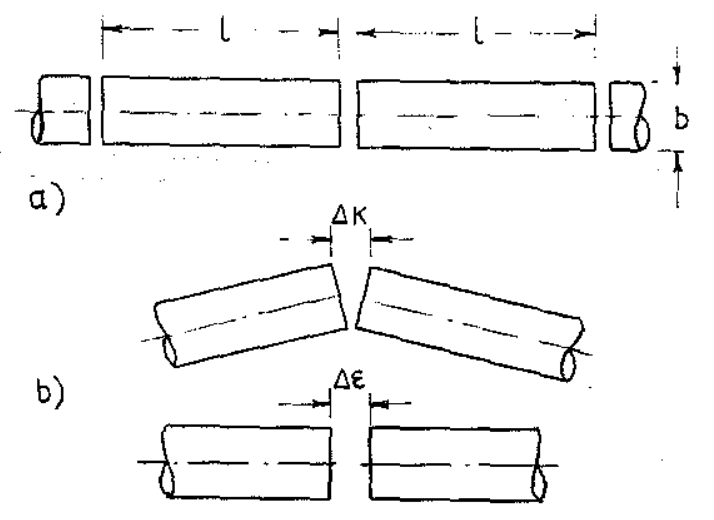

Fig. 8. Movement at the joints

\section{REFERENCES}

1. Richert E., Hall R., Woods D. Vibrations of soils and foundations. Englewood Cliffs (NJ): Prentice-Hall 1970.

2. Roesset M. Fundamentals of soil amplification. In: Hansen R.: Siesmic design for nuclear power plants. Cambridge (Mass.): MIT-Press 1970.

3. Newmark N., Rosenblueth E. Fundamentals of earthquake engineering. Englewood Cliffs (NJ): Prentice-Hall 1971.

4. Timoshenko S., Goodier N. Theory of elasticity. New York: McGraw-Hill 1951.

Received November 11, 1994

\section{TÍNH CÁC KẾT CẤU ỐNG TRONG ĐẤT DƯớI TÁC DỤNG CỮ ĐộNG ĐẤT}

Tác giả nghiên cứu sự làm việc của các kết cấu ống năm trong lòng đất dưới tác dụng của động đất. Ơ̛ đây, hệ các lớp ngang cưa đất được coi như những thanh tổ hợp chịu cắt, còn kết cẩu như những thanh chịu uốn. Giả thiết đất và kết cấu đều làm việc trong trạng thái đàn hồi.

Sử dụng lý thuyết truyền sóng và các giả thiết nêu trên, tác già đã đưa ra phương pháp tính chuyển vị và nội lực trong kết cấu công trình, đồng thời chl rố các tham số ảnh hưởng đến chúng. 